\title{
Power plants on the liberalized Croatian electricity market and environmental protection
}

\author{
I. Androcec \& T. Tarnik \\ Hrvatska elektroprivreda dd, Development Department, Croatia
}

\begin{abstract}
The topic of this paper is the impact of power system restructuring, electricity market introduction, and strengthening of the environmental protection legislation, especially regarding emissions from power plants. Competition in the generation and supply of power provides new business opportunities and strategic business alliances with partners at home and abroad, especially after the introduction of the Energy Community Treaty. A short review of the situation in Croatia regarding liberalization is presented. The analysis of possible variants of the establishment and development of market relations is made, as well as of the corresponding repercussions on short-term and long-term power plant operation and development. Electricity prices are still being regulated by the state and a small share of industrial consumers. Electricity consumption is around $17 \mathrm{TWh}$ which is increasing, supplied by a relatively large share of hydropower plants. This has implications on the development of the power generation sector in Croatia as well as on electricity market operation.

Environmental protection in the energy sector implies the primary action in connection with energy efficiency, renewable sources, choice of energygenerating products and application of state-of-the-art protection technologies, quality legislation and supervision, public opinion and education, and promotion of best practices. In this regard the National Environmental Strategy and National Environmental Action Plan has determined its long-term emission reduction objectives for the main air pollutants, in accordance with existing and future obligations related to mitigation of climate change. Hydropower plants and water reservoirs hold high potential for electricity production, but also pose the threat of changing water regimes and negative effects on eco-systems. Keywords: electricity market, power plants, environmental protection, Croatia.
\end{abstract}




\section{Introduction}

Croatia has been reforming its energy sector on market principles and competition in energy business. The energy sector reform is especially demanding in the area of electrical energy. The Republic of Croatia (which in 2004 obtained the status of a candidate for accession to the European Union and is now in the screening process), and the Croatian electricity company - HEP (which strives to be a full and equal participant in the European electricity market) have been working at an accelerated pace to meet the requirements of the European Commission. Under the Electricity Market Act [1], eligible customers can freely choose their electricity supplier. Since July 1, 2006, eligible customers have all been customers with an annual consumption of over $9 \mathrm{GWh}$. Further opening of the electricity market is set:

- by July 1, 2007 for customers in the commercial category,

- $\quad$ by July 1, 2008 for all customers

As a consequence, new suppliers and traders will enter the market.

The Energy Community Treaty, signed on $25^{\text {th }}$ October, 2005 in Athens and ratified by the Croatian Parliament in May, 2006, is a process that aims to extend the EU internal energy market to the South East Europe region (SEE region). It is a basic document, which integrates Croatia in the energy system of the European Union, even before the official accession. The main goals are to create a stable and regulatory market framework capable of attracting investment, to create a single regulatory space for trade, to enhance security of supply, to improve the environmental situation and to develop electricity and gas market competition on a broader geographical scale. With this Treaty, Croatia will enhance its security of energy supply. National companies will have the possibility to enter into the energy markets of the EU and South East Europe and at the same time foreign companies will have the opportunity to extend their operations in the SEE region. Competition in generation and supply provides new business opportunities (like expansion of other energy and non-energy business) and strategic business alliances with partners at home and abroad.

\section{Croatian electricity market}

The framework for performing energy activities in the electricity market is established by energy related acts, while secondary legislation elaborates legal provisions. In Croatia we distinguish the public service obligation of tariff customers' electricity supply, and the electricity market. According to the Electricity Market Act, tariff customers are supplied by the energy entity having public service obligation of tariff customers' electricity supply. This task is performed by HEP Group. Electricity prices for tariff customers are regulated by the Energy Act and the Tariff System for Energy Activities Performed as Public Services. The number of tariff customers shall decrease by gradual market opening.

The model of a bilateral market, which is chosen in Croatia, is based on electricity trading through bilateral contracts. Contractual parties in the 
electricity supply contract are the customer and the supplier. Bilateral contracts concerning electricity trade (purchase or sale) are concluded between the supplier, the trader or the producer. Besides the supply contract or electricity trade contract, the eligible customer and producer shall conclude a contract for using the network with HEP-Transmission System Operator (HEP-TSO) or with HEP-Distribution System Operator (HEP-DSO) depending on the voltage level the eligible customer is connected to. HEP-TSO is in charge of procuring electricity necessary for system balancing. Each producer, supplier and trader is responsible to HEP-TSO for deviations from its contractual schedule.

PUBLIC SERVICE

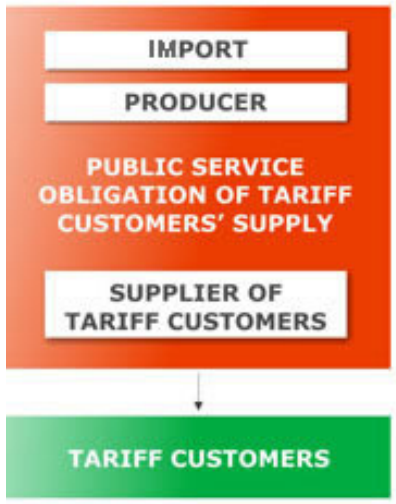

ELECTRICITY MARKET

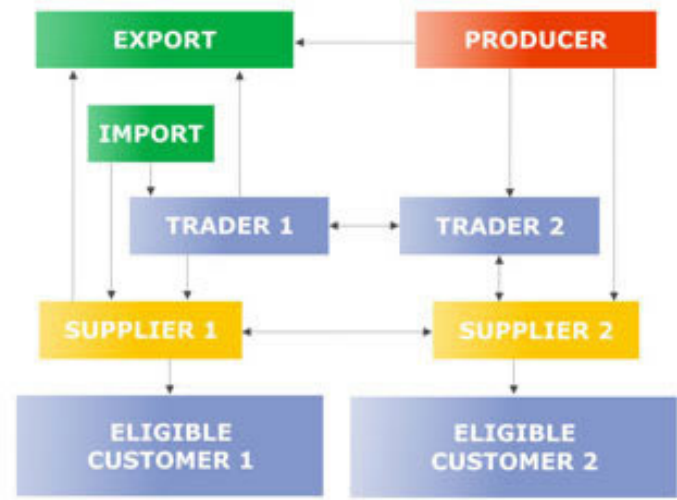

- contractual relationships

Figure 1: Croatian Electricity Market Model.

A market participant in the Croatian electricity market is any producer, supplier, trader or eligible customer. A producer, supplier and trader must have a license for performing energy activity, issued by the Croatian Energy Regulatory Agency. The organization of the electricity market, electricity transmission and distribution are regulated activities performed as public services:

- HROTE is responsible for the organization of the electricity market,

- HEP-TSO is responsible for electricity transmission, maintenance, development and construction of transmission system, and power system control,

- HEP-DSO is responsible for electricity distribution, maintenance, development and construction of distribution system.

Regulated energy activities performed as public services also include electricity production for tariff customers and electricity supply of tariff customers. Both activities are performed by HEP Group as a part of a common and integral task of the energy entity having a public service obligation of tariff customers' electricity supply.

A producer can sell the electricity produced in his own generating facilities to a trader, a supplier, HEP-TSO for system services, transmission network losses 
or system balancing, and HEP-DSO for distribution network services or distribution network losses. There are three types of producers in Croatia:

$\circ$ a producer within the system of the public service, as an energy entity performing the public service obligation of tariff customers' electricity supply,

- an eligible producer,

○ an independent producer.

An eligible producer is a producer which can obtain the status through generating electricity from the renewables and cogeneration. The Energy Act, the Electricity Market Act and secondary legislation regulate incentivizing such electricity generation as well as the purchase/sale of electricity generated from the renewables and cogeneration. HEP-TSO and HEP-DSO are obligated to take an entire amount of generated electricity from an eligible producer. The energy entity responsible for electricity supply is obligated to off-take a minimal share of electricity generated by incentivized eligible producers in accordance with the prescribed conditions (the regulation passed by the Croatian Government). An eligible producer, apart from hydropower plants larger than $10 \mathrm{MW}$, can acquire the right to an incentive through the Tariff system for generating the electricity from renewable energy sources and cogeneration.

The procedure for change of supplier is prescribed by the General Conditions of Electricity Supply (Official Gazette 14/2006). The procedure is free of charge unless nonstandard services of HEP-TSO or HEP-DSO are required. In such a case, all nonstandard services have to be paid according to the price list for nonstandard services, which is published by HEP-TSO or HEP-DSO.

Table 1: $\quad$ Balancing energy prices.

For a supplier

Off-taking more electricity than scheduled Supplier pays to HEP-TSO (Realized - Scheduled $>0$ ) according to unit price $\mathrm{C}_{\mathrm{p}}$

Off-taking less electricity than scheduled HEP-TSO pays to supplier (Realized - Scheduled $<0$ ) according to unit price $\mathrm{C}_{n}$

\section{For a producer or a trader}

Delivering more electricity than scheduled HEP-TSO pays to producer or trader (Realized - Scheduled $>0$ ) according to unit price $\mathrm{C}_{n}$

Delivering less electricity than scheduled Producer or trader pays to HEP-TSO (Realized - Scheduled $<0$ ) according to unit price $\mathrm{C}_{\mathrm{p}}$

\section{For an incentivized eligible producer}

Monthly produced electricity

Market Operator pays to HEP-TSO according to unit price $\mathrm{C}_{\mathrm{nov}}$

Unit prices $C_{p}, C_{n}$ and $C_{\text {pov }}(\mathrm{kn} / \mathrm{MWh})$ of balancing energy for the previous month are published by HEP-TSO on its web pages.

During realization of bilateral supply contracts and electricity trade contracts deviations between realized and scheduled values are present. Since the power system operation is based on the balance between the electricity demand and 
supply, there is a constant need for system balancing. The real time system balancing is the responsibility of HEP-TSO. In order to cover power system deviations in each hour, HEP-TSO offers balancing energy for sale or purchase to market participants. HROTE calculates the balancing energy, and HEP-TSO according to the calculation charges balancing costs from balance responsible parties. Balance responsible parties are any producer, supplier and trader. Each of them shall enter into the balancing energy contract with HEP-TSO. Calculation and billing of balancing energy are carried out in accordance with Balancing Energy Rules. Balancing energy is calculated for each hour according to the difference between delivered electricity and scheduled values. The balancing energy calculation unit is $0,1 \mathrm{MWh}$. HROTE calculates balancing energy monthly, and based on that calculation, HEP-TSO issues to each balance responsible party (BRP) a monthly invoice.

According to the Privatization Act [2], HEP dd is to be privatized in the following way: Croatian Homeland War veterans and their families will receive, without compensation, $7 \%$ of the shares; up to $7 \%$ will be sold to current and former HEP employees under special privileges prescribed by the Government; at least $15 \%$ of the shares will be offered to the Croatian nationals through a public offering with pre-emptive rights and privileges determined and prescribed by the Government, and to the national legal entities and foreign investors without any special rights or privileges; the remaining shares will be offered on the capital market subject to the market circumstances and to the decision of the Government on this matter; and another part of the shares will be set aside for compensation to former owners. However, no one can in no way (directly or indirectly through connected companies) acquire more than $10 \%$ of the voting shares. It should be noted that $51 \%$ of the shares will remain in the ownership of the Republic of Croatia until the accession of the Republic into the European Union.

\section{Power plants on Croatian electricity market}

Since 1 July 2002, the activity of electricity generation has been performed by the company HEP Generation doo. HEP Generation is a limited liability company licensed to perform two energy businesses: electricity generation for tariff customers and electricity generation for the market. Under the Electricity Market Act, the key activity will be electricity generation for tariff customers and responsibility for ancillary services.

The existing generating capacities in Croatia (4090 MW) can meet current electricity demand for more than 2,200.000 customers under average hydrology conditions. A total of $2078 \mathrm{MW}$ of hydroelectric capacity in Croatia is installed in 21 large hydro power plants and in nine small hydro power plants. A total of $1658 \mathrm{MW}$ is installed in 8 thermal power units fired by oil, natural gas or coal. HEP is a partner in a joint-venture coal fired thermal power plant (Plomin 2 TPP) with RWE Power. HEP also owns $50 \%$ of a nuclear power plant (Krško NPP) located on the territory of Slovenia - 338 MW. In addition to HEP's generation, the electricity in Croatia is also generated in small-size industrial 
plants and privately owned renewable electricity sources. However, such generation is irrelevant since it accounts for approximately $1 \%$ of total electricity generation.

The Croatian power generation sector is affected by power system restructuring, the introduction of the electricity market and the possibility of privatization. A number of constraints specific to the Croatian power sector that are taken into account are:

- The relatively small size of the system: Generation in particular poses a problem in the creation of effective competition given the relatively small number of generating plants. However, its location and interconnections with neighboring markets imply that effective competition is achievable.

- The current importance of hydro generation and the small number of major thermal plants: the presence of a significant proportion of hydro power plants in the system does impose certain constraints in the design of power market arrangements. These arise from (a) special operating characteristics of hydro plants and appertaining cost structure and (b) limited competitiveness of thermal plants in some sectors of the load curve [Hydro power plants generate only operating and maintenance costs (and occasionally costs connected with the refurbishment), so that the production costs are on average much lower than those of thermal plants costs or e.g. the average price on the neighboring electricity markets. Hydro plants cover the majority of the variable part of daily load, and the peak load completely. The surplus of peak power and energy is also frequent, and there are good prospects for their placement on foreign electricity markets. Hydro power plants can be divided into few rational parts according to their interrelationship (cascading hydro networks).].

- Take-or-pay fuel contracts applying to some plants: it is understood that take-or-pay gas contracts are in place for fuel supplies to some thermal plants. Depending on the duration and exact terms of these contracts these may present some transitional difficulties with the introduction of competition in generation business.

- CHP plants: a number of thermal power plants that supply the Croatian power system are CHP plants which, in the winter season, have to operate as inflexible generators to meet their heat output requirements.

- Major interconnections with neighboring systems: in some respects a large extent of interconnections may be seen as a constraint, since it can have adverse impact on the security of supply if it results in heavy reliance on imports from other systems. However, such interconnections also provide important sources of competition, and further encourage feasible development of a competitive market.

Due to limited duration of the public service obligation for customer supply (Energy Community, Directive 2003/54/EC) HEP will be adjusted to dynamic market opening as a two-sided process (loss of domestic and expansion to external market). Business cooperation will be broadened and business 
connections will be realized through joint venture projects, joint appearance on third markets and through regional associations [3].

\section{Environmental protection aspects}

The principal objectives of the energy policy of the Republic of Croatia are stated in the Energy Sector Development Strategy. Croatia's energy sector development strategy respects to a great extent the environmental protection requirements, focusing the long-term directions of this sector to the following objectives:

- Improvement of energy efficiency from the production, transformation, transmission and transportation to distribution and consumption of energy, which includes encouraging the process of gas pipeline installation and possibilities of gas usage, and generation of energy outside public networks,

- Utilization of renewable sources of energy which will be in accordance with sources, technological development and economic policy,

- Environmental protection which in the energy sector implies the primary action in connection with energy efficiency, renewable sources, choice of energy-generating products and application of state-of-the-art protection technologies, quality legislation and supervision, the public opinion and education and promotion of best practices.

In order to meet the objectives mentioned above the Croatian Parliament adopted National Environmental Strategy [4] and National Environmental Action Plan (NEAP) as its implementation document [5]. NEAP contains detailed action plans for thematic areas of environmental protection in the various sectors, and also for the energy sector. Environmental protection objectives for the power sector are the following [6]:

- Reduction of emissions into water, air and soil

- Energy efficiency increase,

- Modification of technology for generation of energy and fuels for power industry in an environmentally acceptable manner,

- Introduction of prevention measures with the aim to reduce the number of accidents,

- Development of a data collection and database system (electronic version),

- Reduction of the age of components and equipment built in power generation facilities.

Environmental protection has been recognized as an important element in the operation of all companies within the HEP Group, not only in the function of development and strategic planning but also as a part of regular operation of power facilities. This belief has been formally outlined in the Business Plan of the Management Board of HEP and in Operating Programmes of individual companies. The Business Plan of HEP's Management Board commits the HEP 
Group to operate on the principles of cost-effectiveness and transparency to the highest environmental standards and to improve public and customer relations.

In order to implement its own environmental policy and shows its commitment to meeting national environmental priorities, in particular the reduction of greenhouse gas emissions in line with the Kyoto Protocol, and the priorities stemming from the national energy strategy and relating to the promotion of the use of renewable energy sources, HEP entered into a long-term power purchase agreement with private investitors and takes over electricity from 3 wind parks, Ravne (total installed capacity 5.95 MW), Trtar (11.90 MW), and Jesenice (10.80 MW), and from a small landfill-gas fired thermal power facility, Jakuševac (2MW). HEP also encourages the implementation of several pilot projects, especially those applying the technology of electricity and heat cogeneration with biomass as the primary fuel and geothermal.

Although even now electricity generation by hydroelectric power plants of HEP accounts for more than a half of the total electricity generated (depends on amount of rainfall during the year), HEP endeavors to increase the share of renewable energy sources. All hydroelectric power plants owned by HEP earned green certificates for electricity generation from renewables. The award of certificates and their periodical verification was carried out to the TÜV standard "CMS-Kriterien Erzeugung EE" for producers of energy from renewable sources. The certification of generation assets represents the first step towards selling electricity in the market. To increase efficiency of its TPP, HEP commissioned in 2003 a gas-fired combined cycle cogeneration plant. This plant fires natural gas and meets the most stringent international environmental standards [6].

In addition to energy generation from renewables, HEP encourages the development of demand side management and energy efficiency measures. Energy efficiency projects include the reconstruction and rehabilitation of the existing plants and facilities with an aim to improve engineering designs and rationalize energy consumption, assuming investment payback from energy savings. The environmental impact, caused by pollutant emissions and waste generation, is directly linked to the achieved energy efficiency at end-users. Therefore, the same motivations drive environmental impact abatement and energy efficiency increase. Although a systematic approach to solving a complex problem of the impact of power plants and facilities on the environment has increasingly been recognized as a key factor, besides technology and business performance, in the formulation of energy policy of Croatia there are some seriously environmental pressures [6].

Since Croatia has not ratified the Kyoto Protocol, it does not yet participate in the Kyoto Protocol mechanisms. Croatia is an Annex I country of the UN Framework Convention on Climate Change and a country that has pledged in the Annex B of the Kyoto Protocol to reduce its GHG emissions by 5\%. For the Republic of Croatia, a reduction in emissions of 5\% in the period 2008-2012, in relation to the reference year laid down by the Kyoto Protocol, will, considering the low initial level of emissions, be a difficult task to achieve. Croatia is under negotiation with the international community regarding its base year emission 
level. Resolving that open question is important for the plan of the activity preparation that concrete projects could be implemented regarding fulfillment of Kyoto Protocol obligations. The emissions of greenhouse gases on the territory of Croatia account for less than $0.2 \%$ of the Annex I countries' total emissions, i.e. the per capita emission $6.55 \mathrm{Mt}$ eq- $\mathrm{CO}_{2}$ approaches the lowest emission levels amongst these countries. The reason for that is in the renewable energy sources extensively used, hydro-power plants contribution with $40-60 \%$ to electricity generation, meeting $15 \%$ of the electricity demand from cogeneration, 15 to $20 \%$ from nuclear power plant, $5 \%$ of total energy demand by energy utilization of biomass, while, share of coal in total energy demand is only $2 \%$. In the Document "Projections of GHG emissions", Croatia presented three different emission scenarios - a scenario without measures, a scenario with measures and a scenario with additional measures. The results indicate that Croatia would overshoot its Kyoto target based on the emissions of the year 1990 by $6.1 \mathrm{Mt}$ eq$\mathrm{CO}_{2}$ in the first scenario, by $5.22 \mathrm{Mt}$ eq- $\mathrm{CO}_{2}$ in the second scenario and by $1.3 \mathrm{Mt}$ eq- $\mathrm{CO}_{2}$ in the third scenario. After the initial drop in emissions between 1990 and 1995 driven by the war and deteriorated economic conditions, the emissions started to rise again. Still, in 2000 Croatia met the stabilization aim of the UNFCCC, since its emissions were below the 1990 emission level. Given that the bulk of emissions in Croatia come from energy, it is well understood that climate change mitigation measures in this sector are of particular significance for the response strategy. So far, however, the only progress made in moving towards less carbon-intensive fuels took the form of a very slight increase in the share of natural gas and there are prospects of a further increase in the near future, together with maintaining the share of renewables in meeting the energy demand growth. Notwithstanding some ongoing pilot actions and the relevant aspects of the legislation on energy market liberalization, the policy to promote energy efficiency and to increase further the share of renewables are on an advanced stage of implementation. Moreover, the work on secondary legislation is also under way to ensure, among other things, that the environmental objectives are met in the process of energy market liberalization, including provisions for renewable energy and energy efficiency [5].

Emissions trading, as set out in Article 17 of the Kyoto Protocol, provides for Annex I Parties to acquire units from other Annex I Parties and use them towards meeting their emissions targets under the Kyoto Protocol. This enables Parties to make use of lower cost opportunities to reduce emissions, irrespective of which Party those opportunities exist, in order to lower the overall cost of reducing emissions. Only Annex I Parties to the Kyoto Protocol with emission limitation and reduction commitments inscribed in Annex B to the Protocol may participate in such trading. Such Parties may therefore be prepared to transfer units when they do not require them for compliance with their own emission targets. The units which may be transferred under Article 17 emissions trading each equal to one metric tonne of emissions (in $\mathrm{CO}_{2}$-equivalent terms). Emission trading could be an effective mechanism for Croatia to achieve the Kyoto Protocol target but as mentioned above since Croatia has not ratified the Kyoto Protocol, it does not yet participate in Kyoto Protocol mechanisms. 


\section{Conclusion}

Energy sector reform in the Republic of Croatia is underway, in line with EU legislation. The reform includes setting up of the Croatian electricity market and HEP Group's restructuring, governed by a set of national energy laws. HEP would like to stay a reputable European electrical utility with regards to business practices, performance and high quality service. Environmental protection and emission trading have a remarkable impact on power plant operation and, after making of the National Allocation Plan, this will impact on merit order and investments. Investments in renewables, cogeneration, energy efficiency and low $\mathrm{CO}_{2}$ emisions technology are changing the power sector, as well as market opening and starting of the privatization process. HEP plans to remain the leading Croatian electrical utility once a competitive environment is achieved, as well as to extend its business in the region.

\section{References}

[1] Official Gazette, 2004: Electricity Market Law, Croatia, 2001 \& 2004

[2] Official Gazette, 2002, Privatization Act of Hrvatska elektroprivreda, Croatia

[3] Training Centre for Energy Trading, http://www.tcet.info/

[4] National Environmental Strategy, Ministry of Environmental Protection and Physical Planning (2003)

[5] National Environmental Action Plan (NEAP), Ministry of Environmental Protection and Physical Planning (2003)

[6] HEP and the Environment 2003-2004, Croatian Power Company (2006) 